\title{
Analisa Pengaruh Penggunaan Sensor Oksigen Terhadap Kandungan Emisi Gas Buang CO Dan HC
}

\author{
Analysis of Effect of Use Oxygen Sensor Exhaust \\ Emission of Content CO And HC
}

\author{
Dwi Sudarno Putra, Donny Fernandez \& Gito Giantoro
}

Jurusan Teknik Otomotif Universitas Negeri Padang Email : dwisudarnoputra@gmail.com , fernandez_79@yahoo.co.uk dan giantoro.gito@yahoo.co.id

\begin{abstract}
The use of oxygen sensors on vehicles intended to reduce the harmful content from vehicle exhaust emissions. Research and journal was prepared to find how much reduction can be achieved. Research conducted by the experimental method. This type of machine used is K3-VE engine Avanza. Measurements are performed using the exhaust emission analyzer Fourgas at some level of engine speed.

From the research proven when using oxygen sensors decrease harmful content of exhaust emissions. The decline in the percentage of the CO content of $1.86 \%$ and the average number of $\mathrm{HC}$ ppm reduced the total 258.33ppm.
\end{abstract}

Keywords: Oxygen Sensors, Sensors Automotive Exhaust Emissions

\section{PENDAHULUAN}

Semakin tingginya angka pencemaran udara diberbagai kota besar di indonesia saat ini semakin memprihatikan. Kondisi udara tidak sepenuhnya bersih, karena gas buang hasil dari pembakaran kendaraan mengandung racun yang berbahaya bagi lingkungan, terutama Karbon Monoksida (CO), Hidrokarbon (HC) dan Nitrogen Oksida $\left(\mathrm{NO}_{\mathrm{x}}\right)$. Terlepas dari seberapa sempurna mesin beroperasi , akan selalu ada beberapa gas berbahaya dari hasil pembakaran. Sumber polusi yang utama berasal dari transportasi, di mana hampir $60 \%$ dari polutan yang dihasilkan terdiri dari karbon monoksida dan sekitar $15 \%$ dari hidrokarbon (Fardiaz, 1992).

Bagi masyarakat, kendaraan merupakan urat nadi kehidupan sehari-hari dan merupakan salah satu kebutuhan pokok yang sangat penting. Kemajuan teknologi dan kemajuan di bidang ekonomi membawa pada konsekuensi peningkatan pendapatan masyarakat menyebabkan kesempatan kepemilikan kendaraan semakin meluas. Di samping sisi positif peningkatan kepemilikan kendaraan bermotor yang berjalan begitu cepat, ternyata muncul sisi negatif yang tidak dapat dielakkan. Sisi negatif tersebut antara lain berupa kemacetan lalu lintas sampai masalah pencemaran udara sehingga dikhawatirkan akan membahayakan dan mempengaruhi kualitas lingkungan hidup. Hal ini mengakibatkan meningkatnya pencemaran udara di indonesia.

Dalam mendukung usaha pelestarian lingkungan hidup, Negara-negara didunia mulai menyadari bahwa gas buang kendaraan merupakan salah satu polutan atau sumber pencemar udara terbesar, oleh karena itu gas buang kendaraan harus dibuat sebersih mungkin agar tidak mencemari udara.

Perkembangan teknologi dan kemajuan ilmu pengetahuan mobil zaman sekarang telah menggunakan sistem EFI (Electronic Fuel Injection). EFI adalah sebuah sistem penyemprotan bahan bakar yang dalam kerjanya dikontrol secara elektronik agar didapatkan nilai campuran udara dan bahan bakar selalu sesuai dengan kebutuhan motor bakar, sehingga didapatkan daya motor yang 
optimal dengan pemakaian bahan bakar yang minimal serta mempunyai gas buang yang ramah lingkungan. Untuk memperoleh emisi gas buang yang berwawasan lingkungan diperlukan perbandingan campuran yang ideal atau yang mendekati ideal disegala kondisi operasional motor. Agar mendapatkan perbandingan campuran yang ideal tersebut dibutuhkan informasi keadaan campuran udara bahan bakar yang harus diterima oleh ECU, informasi atau sinyal diterima dalam bentuk tegangan berdasarkan kadar oksigen yang ada pada saluran gas buang, fungsi tersebut dilakukan oleh oksigen sensor (PT. Toyota Astra Motor. 2004).

\section{Proses Pembakaran}

Secara umum pembakaran didefinisikan sebagai reaksi kimia atau reaksi persenyawaan bahan bakar dengan oksigen dengan diikuti oleh sinar dan panas. Mekanisme pembakaran sangat dipengaruhi oleh keadaan dari keseluruhan proses pembakaran dimana atom-atom dari komponen yang dapat bereaksi dengan oksigen dan membentuk produk yang berupa gas.

Sebagai mana telah kita ketahui sebagai bahan bakar motor bensin terutama mengandung unsur-unsur carbon dan hidrogen. Ini dikenal dengan teori mengenai terbakarnya hidrokarbon tersebut.

Hidrokarbon terbakar bersama-sama dengan oksigen sebelum karbon bergabung dengan oksigen. (2) Carbon terbakar lebih dahulu dari pada hidrogen.(3) Senyawa hidrokarbon terlebih dahulu bergabung dengan oksigen dan membentuk senyawa yang kemudian dipecah secara terbakar (thermis).

Ada beberapa faktor yang dapat mempengaruhi proses pembakaran di dalam silinder ini. Faktor-faktor tersebut ialah : temperatur, kerapatan campuran, komposisi, dan turbulensi yang ada pada campuran.

Ada kemungkinan yang dapat terjadi pada pembakaran motor bensin yaitu : (1) Pembakaran sempurna (normal) yaitu dimana bahan bakar dapat terbakar seluruhnya pada saat dan keadaan yang dikehendaki. Mekanisme pembakaran yang sempurna (normal) dimulai pada saat terjadi loncatan bunga api pada busi. Selanjutnya api membakar campuran bahan bakar udara dan terus menjalar keseluruh bagian campuran sampai semua partikel-partikel campuran bahan bakar dan udara terbakar habis. Di dalam pembakaran normal, pembagian nyala api pada waktu ignition delay terjadi diseluruh bagian.

Pada keadaan yang sebenarnya mekanisme pembakaran di dalam motor ini bersifat komplek, dimana ini berlangsung beberapa fase. Yang paling penting kita ketahui adalah adanya proses perambatan api dan adanya pembakaran (combustion). Pada saat gas bakar dikompresikan, tekanan dan suhunya naik, sehingga terjadi reaksi kimia dimana molekul-molekul hidrokarbon terurai dan bergabung dengan oksigen dan udara. Bentuk ruang bakar yang dapat menimbulkan turbolensi pada gas tadi akan membuat gas bakar tersebut dapat bercampur dalam keadaan homogen.

Sebelum langkah kompresi berakhir terjadilah percikan api pada busi yang kemudian membakar gas bakar tersebut. Dengan timbulnya energi panas, tekanan dan suhu naik secara mendadak sehingga torak terdorong menuju titik mati bawah (TMB). (2)Pembakaran tidak Sempurna (tidak normal). Pembakaran tidak sempurna adalah pembakaran yang terjadi di dalam silinder dimana nyala api dari pembakaran ini tidak menyebar dengan teratur dan merata sehingga menimbulkan masalah atau bahkan kerusakan pada bagian-bagian dari motor dapat terjadi akibat dari pembakaran yang tidak sempurna atau dimana sebagian bahan bakar tidak ikut terbakar, atau tidak terbakar bersama-sama pada saat dan keadaan yang dikehendaki.

Knocking merupakan suatu proses pembakaran dari campuran bahan bakar dengan udara tanpa menggunakan percikan bunga api dari busi. Dalam hal ini campuran bahan bakar dan udara terbakar dengan sendirinya yang di sebabkan oleh naiknya tekanan dan temperatur yang tinggi didalam selinder. Sebagai akibatnya tenaga mesin 
akan berkurang dan jika sering terjadi akan memperpendek umur mesin.

Pre-ignition peristiwanya hampir sama dengan knocking tetapi terjadinya pada saat busi belum memercikan bunga api. Disni campuran bahan bakar udara terbakar sendiri sebagai akibat dari tekanan dan suhu yang tinggi sebelum terjadinya busi menyala. Biasanya bersuara lebih keras dan tenaga yg terbuangpun lebih banyak (sangat ngedrop). Akibat dari kinerja ini akan mengakibatkan batang torak menjadi bengkok.

Pembakaran yang tidak lengkap yaitu pembakaran yang ada kelebihan, kekurangan oksigen atau hidrogen.

\section{Teknologi ECM}

Electronics Control Module (ECM) menjadi bagian tak terpisahkan dari perkembangan teknologi Otomotif saat ini. Mulai dari sistem Salah satu aplikasi di dalam sistem ECM ini adalah sistem sistem penyemprotan bahan bakar yang dalam kerjanya dikontrol secara elektronik agar didapatkan nilai campuran udara dan bahan bakar selalu sesuai dengan kebutuhan motor bakar, sehingga didapatkan daya motor yang optimal dengan pemakaian bahan bakar yang minimal serta mempunyai gas buang yang ramah lingkungan. Untuk memperoleh emisi gas buang yang berwawasan lingkungan diperlukan perbandingan campuran yang ideal atau yang mendekati ideal disegala kondisi operasional motor. Agar mendapatkan perbandingan campuran yang ideal tersebut dibutuhkan informasi keadaan campuran udara bahan bakar yang harus diterima oleh ECU, informasi atau sinyal diterima dalam bentuk tegangan berdasarkan kadar oksigen yang ada pada saluran gas buang, fungsi tersebut dilakukan oleh oksigen sensor (PT. Toyota Astra Motor. 2004).

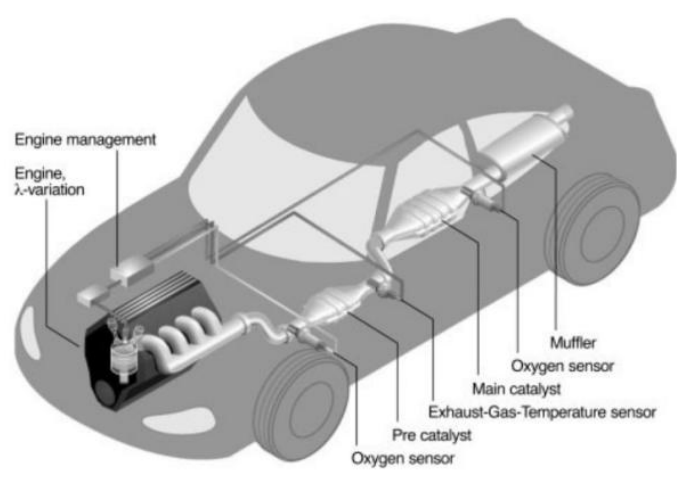

Gambar 1. Sistem Gas Buang (J.Marek, 2003).

Sistem penyemprotan bahan bakar pada beberapa merk kendaraan berbeda istilahnya, oleh Toyota sistem ini dikenal dengan Electronics Fuel Injections (EFI). Sedangkan di Honda disebut dengan PGM-FI (Programmed Fuel Injections)

\section{Sensor Oksigen}

Pada aplikasi otomotif, oksigen sensor digunakan untuk mengukur perbandingan Udara dan Bahan bakar ( $A / F$ Ratio) pada bagian gas buang dan untuk mengendalikan kondisi optimal dari $A / F$ Ratio demi sempurnanya gas buang setelah perlakuan yang dilakukan di catalityc-converter (J.Marek, 2003).

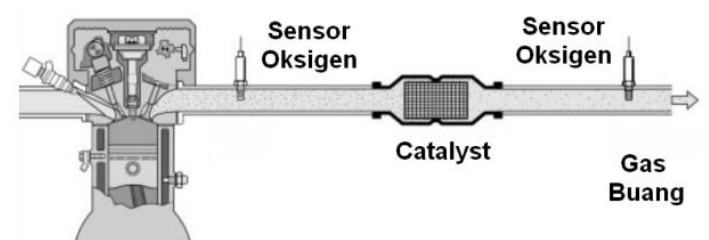

Gambar 2. Sistem Gas Buang Setelah Perlakuan (J.Marek, 2003).

Oksigen sensor yang dipasangkan pada saluran gas buang sebelum katalik konverter, dengan demikian katalitik konverter hanya akan mereduksi kadar racun pada emisi setelah diperoleh perbandingan campuran yang mendekati ideal. Sensor oksigen ini terbuat dari zirconia, elektroda platinum, dan pemanas. 


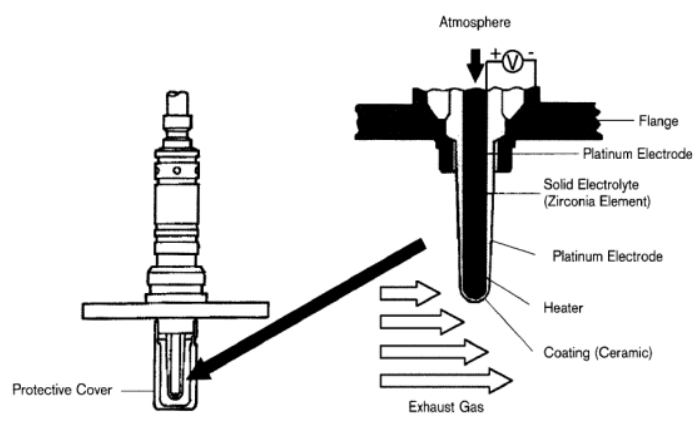

Gambar 3. Konstruksi Sensor Oksigen (PT. Toyota Astra Motor. 2004)

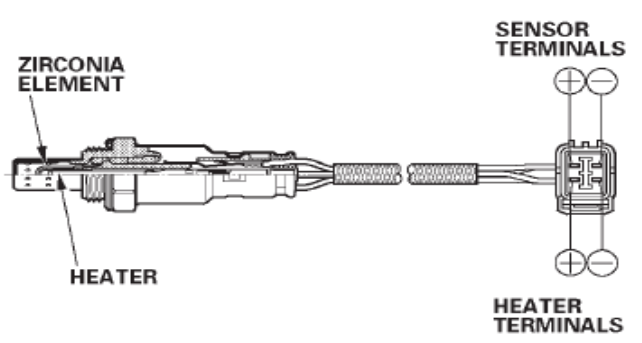

Gambar 4. Bagian Oksigen Sensor (PT. Honda Prospect Motor, 2002).

Tipe dari sensor ini berbeda tergantung jenis mesin yang digunakan. Sensor oksigen zirconia (zirconia oxygen) ada yang menggunakan pemanas (heater) yang memanaskan elemen zirconia. Pemanas ini dikontrol oleh ECU. Bila volume udara masuk rendah (yaitu, bila temperatur gas buang rendah, maka arus listrik mengalir ke pemanas (heater) untuk memanaskan sensor). Okigen sensor yang digunakan pada Avanza ini adalah oksigen sensor jenis zirconia yang sudah menggunakan heater. Heater sudah terintegrasi di dalam beberapa tipe oksigen sensor yang berfungsi untuk membantu okigen sensor segera bekerja pada saat setelah engine start.

Zirconia (semacam material keramik) dimana zirconia untuk melindungi elemen sensor, sebuah cover untuk mengarahkan emisi exhaust dan sebuah terminal penghubung untuk menyalurkan gaya gerak listrik. Elemen ini dilapisi lapisan tipis platina pada bagian dalam dan luarnya.

Sensor oksigen menghasilkan sinyal tegangan berdasarkan jumlah oksigen yang berada didalam dan diluar sensor. Unsur zirconia satu sisi terkena aliran gas buang, sisi lain yang terbuka ke atmosfer. Masingmasing pihak memiliki elektroda platinum yang melekat pada unsur zirconia. Apabila elektroda platinum atau elemen zirconia kotor atau korosi maka output sinyal tegangan akan berkurang.

Bila konsenstrasi oksigen pada permukaan dalam element zirconia lebih berbeda dari pada konsentrasi oksigen di udara luar disaat temperatur elemen zirconia $400^{\mathrm{c}} \mathrm{C}$ atau lebih, maka Elemen zirconia akan membangkitkan tegangan yang bekerja berdasarkan sinyal OX dari ECU.

Bila perbandingan campuran udara dan bahan bakar kurus, di dalam gas buang terdapat banyak oksigen, karna itu sedikit sekali perbedaan konsentrasi antara oksigen pada bagian dalam dan luar sensor. Sehingga tegangan yang terbentuk oleh elemen zirconia rendah mendekati $0 \mathrm{~V}$. Sebaliknya bila campuran udara dan bahan bakar gemuk, oksigen didalam gas buang hampir tidak ada. Hal ini terjadi perbedaan konsentrasi oksigen yang besar di bagian dalam dan diluar sensor sehingga tegangan yang dihasilkan elemen zirconia besar $\pm 1 \mathrm{~V}$.

Platinum yang dilapisi elemen zirconia bekerja sebagai Catalyst, menyebabkan oksigen dan $\mathrm{CO}$ dalam gas buang bereaksi. Hal ini akan mengurangi volume oksigen dan sensitivitas sensor.

Berdasarkan sinyal dari sensor ini, engine ECU menambah atau mengurangi volume penginjeksian agar perbandingan udara dan bahan bakar ideal (mendekati perbandingan teoritis).

\section{Emisi Gas Buang}

Gas buang yang dihasilkan dari pembakaran bahan bakar dan udara terdiri dari banyak komponen gas yang sebagian besar merupakan polusi bagi lingkungan hidup. Sumber polusi yang utama berasal dari transportasi, di mana hampir $60 \%$ dari polutan yang dihasilkan terdiri dari karbon monoksida dan sekitar 15\% dari hidrokarbon. Sumber-sumber polusi lainnya misalnya pembakaran, proses industri, pembuangan limbah dan lain-lain. Polutan yang utama adalah karbon monoksida yang mencapai hampir setengahnya dari seluruh polutan udara yang ada. 
Emisi gas buang adalah polutan yang mengotori udara yang dihasilkan dari gas buang kendaraan. Gas bekas umumnya terdiri dari gas yang tidak beracun $\mathrm{N}_{2}$ (nitrogen), $\mathrm{CO}_{2}$ (gas carbon), dan $\mathrm{H}_{2} \mathrm{O}$ (uap air) dan sebagian kecil merupakan gas beracun seperti : gas $\mathrm{CO}, \mathrm{HC}$, dan $\mathrm{NOx}$ (oksida nitrogen) yang sekarang populer dalam gas bekas maupun gas buang adalah gas yang beracun.

Kandungan gas buang yang dihasilkan kendaraan yang umumnya terdiri dari gas yang beracun yaitu : (1) Karbon Monoksida (CO). Menurut Wisnu "Karbon Monoksida (CO) adalah suatu gas yang tidak bewarna, tidak berbau dan juga tidak berasa. Gas $\mathrm{CO}$ dapat berbentuk cairan pada suhu di bawah $192^{\circ}$ C. Gas CO sebagian besar berasal dari pembakaran bahan bakar fosil dengan udara, berupa gas buangan".(2) Nitrogen Oksida $\left(\mathrm{NO}_{\mathrm{x}}\right)$ Menurut Wardan "Nitrogen Oksida atau disingkat dengan $\mathrm{NO}_{\mathrm{x}}$ adalah emisi yang dihasilkan oleh pembakaran yang terjadi pada temperatur tinggi. Udara bebas yang digunakan untuk pembakaran mengandung nitrogen sekitar $80 \%$. Pada temperatur yang cukup tinggi (sekitar $1370^{\circ} \mathrm{C}$ atau lebih ) nitrogen dan oksigen dalam campuran bahan bakar dengan udara akan bersatu dan membentuk $\mathrm{NO}_{\mathrm{x}}$. Oksida Nitrogen akan menghasilkan warna coklat kotor pada gas buang. Disamping itu juga terasa pedas dimata dan mengganggu paru-paru. $\mathrm{NO}_{\mathrm{x}}$ ini akan bertambah apabila campuran bahan bakar dengan udara yang kurus".

Menurut Wisnu "Nitrogen oksida sering disebut dengan NOx karna oksidasi nitrogen mempunyai 2 macam bentuk yang sifatnya berbeda, yaitu : gas $\mathrm{NO}_{2}$ dan gas NO. Sifat gas $\mathrm{NO}_{2}$ adalah bewarna dan berbau, sedangkan gas NO tidak bewarna dan tidak berbau. Warna gas $\mathrm{No}_{2}$ adalah merah kecoklatan dan berbau tajam menyengat hidung".(3) Hidro Karbon (HC). Menurut Wardan "Hidro Carbon atau HC adalah emisi yang timbul karena bahan bakar yang belum terbakar tetapi sudah keluar bersama-sama gas buang menuju atmosfer. Hal ini bisa dipahami karena bahan bakar yang dipakai pada motor bensin adalah bahan bakar yang terbuat dari hidro carbon". Emisi hidrocarbon ini dapat disebabkan karena pembakaran yang kurang sempurna karna ada penguapan bahan bakar. Pengaruh yang ditumbulkan terhadap manusia adalah menyebabkan mata perih, tenggorokian sakit, paru-paru sakit dan bahkan dapat menyebabkan kanker.

Hidro Carbon yaitu zat yang merupakan ikatan kimia hanya dari hydrogen $(\mathrm{H})$ dan carbon (C) saja. Bila kepekaan HC- nya bertambah tinggi maka akan merusak sistem pernafasan manusia (tenggorokan).

Dari gas buang HC dibagi 2 yaitu : (a) Bahan bakar yang tidak terbakar dan keluar menjadi gas mentah. (b) Bahan bakar terpecah karna reaksi panas berubah menjadi gugusan $\mathrm{HC}$ yang lain, yang keluar bersama gas buang.

Adapun sebab - sebab utama timbulnya HC yaitu : (a) Sekitar dinding-dinding ruang bakar yang bertemperatur rendah dimana temperatur itu tidak mampu melakukan pembakaran. (b) Missing (misfire). Adanya overlap intake valve (kedua valve sama-sama terbuka), jadi merupakan gas pembilas/pembersih.

\section{METODOLOGI}

Penelitian ini merupakan penelitian eksperimen. Peneliti melakukan pengujian pada Mesin Avanza K3-VE, 4 selinder, 16 valve, DOHC, VVT-i, EFI. Pengujian dilakukan secara bertahap memvariasikan putaran yaitu pada putaran $800 \mathrm{rpm}, 1700$ rpm dan 2500 rpm. Pada setiap putaran mengukur Kandungan emisi Karbonmonoksida (CO) dan Hidrocarbon (HC). Agar hasil pengujian lebih akurat maka pengujian ini setiap putaran dilakukan 3 kali pengujian yaitu dengan menggunakan $\mathrm{O}_{2}$ sensor dan tanpa menggunakan $\mathrm{O}_{2}$ sensor.

Pemasangan dan pelepasan Sensor Oksigen serta variasi putaran mesin menjadi acuan utama perbandingan dalam eksperimen ini. Adapun hasil akhir yang dibandingkan adalah kualitas kandungan emisi gas buang $\mathrm{CO}$ dan $\mathrm{HC}$ yang diperoleh menggunakan alat Fourgas Analyzer.

Pengambilan data emisi gas buang dilakukan langsung dengan cara melakukan 
pengujian emisi gas buang pada Mesin Toyota Avanza K3-VE, kemudian hasilnya langsung dimasukan kedalam tabel.

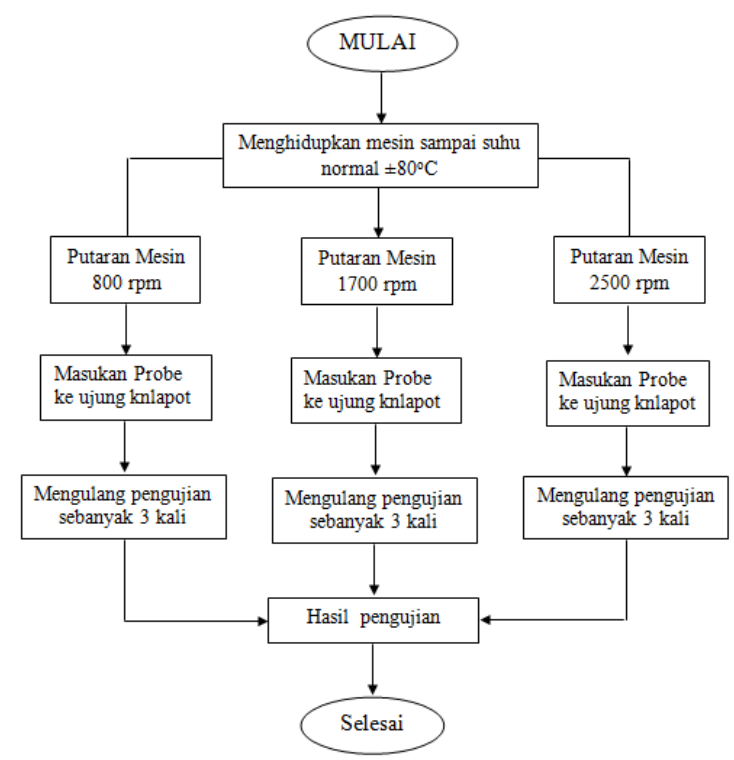

Gambar 5. Diagram Alir Pengujian

Prosedur pengambilan data pengujian emisi gas buang Mesin Toyota Avanza K3VE.

1) Hidupkan mesin sampai temperatur $\pm 80^{\circ}$ C.

2) Operasikan four gas analyzer

a) Power On, biarkan hidup beberapa saat untuk melakukan proses kalibrasi.

b) Ready gas (Stand By).

c) Tekan Ent setelah probe dimasukan keujung knalpot.

d) Bila pengukuran selesai tekan Stand By dan tekan purge (sisa gas dari knalpot di 4 gas dalam proses buang).

e) Otomatis kembali ke Stan By.

f) Bila akan dipakai kembali tekan $E N T$ kembali.

g) Tekan print 2x di panel.

h) Tekan $\boldsymbol{\Delta}$ isi angka yang di mau.

i) Tekan $\boldsymbol{\nabla}$ untuk menggeser dan mengisi angka di barisan ke dua dan selanjutnya.

j) Setelah angka No.Pol mobil lengkap, tekan Print 1x kembali dan hasil akan tercatat di kertas print.

k) Lakukan pengujian sebanyak 3 kali setiap putaran (rpm) yaitu pada putaran 800, 1700, $2500 \mathrm{rpm}$.
HASIL

Setelah dilakukan penelitian diperoleh data seperti pada tabel 1 dan 2 .

Tabel 1. Hasil Pengujian Kandungan Emisi Gas buang Pada Toyota Avanza K3-VE Tanpa Sensor Oksigen

\begin{tabular}{|c|c|c|c|c|c|c|}
\hline \multirow{2}{*}{$\begin{array}{c}\text { Putaran } \\
\text { rpm }\end{array}$} & \multirow{2}{*}{$\begin{array}{c}\text { Suhu } \\
\left({ }^{\circ} \mathrm{C}\right)\end{array}$} & \multirow{2}{*}{ Emisi } & \multicolumn{3}{|c|}{ Tanpa $\mathrm{O}_{2}$ Sensor } & \multirow{2}{*}{ Rata-Rata } \\
\cline { 3 - 6 } & & & Uji I & Uji II & Uji III & \\
\hline $800 \mathrm{rpm}$ & \pm 80 & $\mathrm{CO} \%$ & 2.61 & 1.03 & 0.50 & 1.38 \\
\cline { 3 - 6 } & & $\mathrm{HC}(\mathrm{ppm})$ & 291 & 303 & 272 & 288 \\
\hline $1700 \mathrm{rpm}$ & \pm 80 & $\mathrm{CO} \%$ & 2,78 & 2.08 & 2.27 & 2.37 \\
\cline { 3 - 6 } & & $\mathrm{HC}(\mathrm{ppm})$ & 385 & 406 & 398 & 396 \\
\hline $2500 \mathrm{rpm}$ & \pm 80 & $\mathrm{CO} \%$ & 1.87 & 1.98 & 1.96 & 1.93 \\
\cline { 3 - 6 } & & $\mathrm{HC}(\mathrm{ppm})$ & 293 & 281 & 280 & 284 \\
\hline
\end{tabular}

Tabel 2. Hasil Pengujian Kandungan Emisi Gas buang Pada Toyota Avanza K3-VE dengan Sensor Oksigen

\begin{tabular}{|c|c|c|c|c|c|c|}
\hline \multirow{2}{*}{$\begin{array}{c}\text { Putaran } \\
\text { rpm }\end{array}$} & \multirow{2}{*}{$\begin{array}{c}\text { Suhu } \\
\left({ }^{\circ} \mathrm{C}\right)\end{array}$} & \multirow{2}{*}{ Emisi } & \multicolumn{3}{|c|}{ Menggunakan $\mathrm{O}_{2}$ Sensor } & \multirow{2}{*}{ Rata-Rata } \\
\cline { 3 - 6 } & & & Uji I & Uji II & Uji III & \\
\hline $800 \mathrm{rpm}$ & \pm 80 & $\mathrm{CO} \%$ & 0.04 & 0.09 & 0.04 & 0.06 \\
\cline { 3 - 6 } & & $\mathrm{HC}(\mathrm{ppm})$ & 98 & 105 & 103 & 102 \\
\hline $1700 \mathrm{rpm}$ & \pm 80 & $\mathrm{CO} \%$ & 0.01 & 0.07 & 0.02 & 0.03 \\
\cline { 3 - 6 } & & $\mathrm{HC} \mathrm{(ppm)}$ & 58 & 72 & 47 & 59 \\
\hline $2500 \mathrm{rpm}$ & \pm 80 & $\mathrm{CO} \%$ & 0.02 & 0.03 & 0.02 & 0.02 \\
\cline { 3 - 6 } & & $\mathrm{HC}(\mathrm{ppm})$ & 33 & 32 & 31 & 32 \\
\hline
\end{tabular}

\section{Analisa Grafik}

Berdasarkan data pada tabel 1 dan tabel 2 diperoleh grafik seperti pada gambar 6 dan Gambar 7.

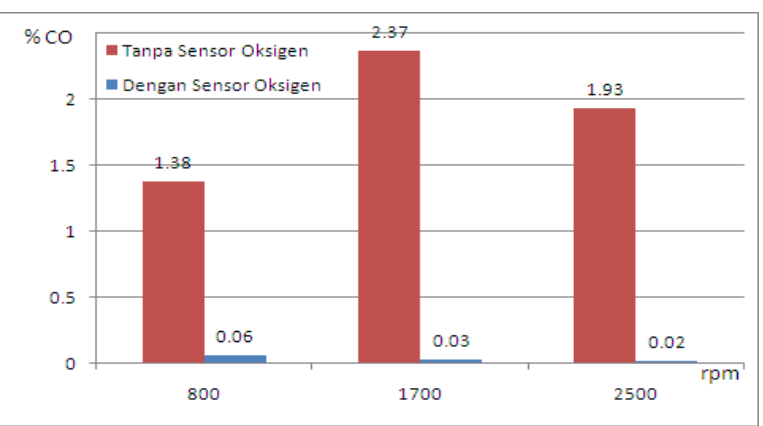

Gambar 6. Grafik perbandingan CO 


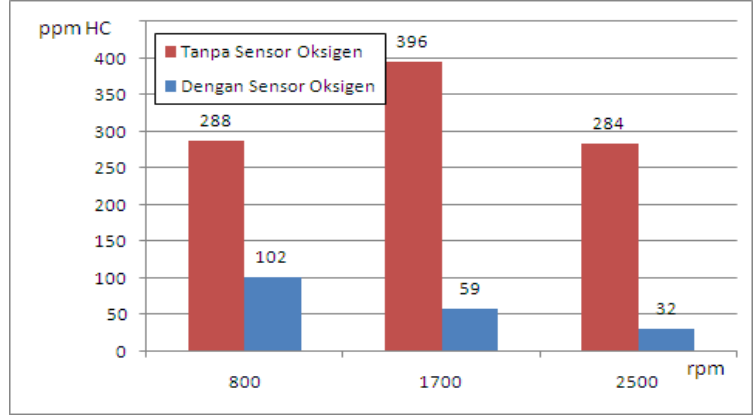

Gambar 7. Grafik perbandingan HC

Kecenderungan yang terlihat pada grafik menunjukkan bahwa saat sensor oksigen diaktifkan maka kandungan \% $\mathrm{CO}$ pada emisi gas buang terlihat menurun. Demikian pula pada kandungan ppm HC pun terjadi penurunan.

\section{PEMBAHASAN}

Tabel 3 merupakan rangkuman data dan analisa statistik sederhana untuk mengetahui pengaruh pemasangan sensor oksigen. Dengan melihat data rerata didapatkan penurunan persentase kandungan $\mathrm{CO}$ sebesar $1.86 \%$ dan rerata jumlah ppm yang berkurang pada $\mathrm{HC}$ sebanyak 258.33ppm.

Jika menjadikan kondisi tanpa sensor oksigen sebagai acuan dan kondisi dengan sensor oksigen sebagai kondisi setelah perlakuan maka setelah perlakuan didapatkan nilai penurunan $\mathrm{CO}$ sebesar $98 \%$ dan untuk nilai penurunan $\mathrm{HC}$ sebesar $80 \%$.

Tabel 3. Analisa Data

\begin{tabular}{|c|c|c|c|c|}
\hline \multirow[b]{2}{*}{$\begin{array}{l}\text { Putaran Mesin } \\
\text { (rpm) }\end{array}$} & \multicolumn{2}{|c|}{$\%$ CO } & \multicolumn{2}{|c|}{ ppm HC } \\
\hline & $\begin{array}{c}\text { Tanpa Sensor } \\
\mathrm{O} 2\end{array}$ & $\begin{array}{c}\text { Dengan } \\
\text { Sensor } 02\end{array}$ & $\begin{array}{c}\text { Tanpa } \\
\text { Sensor O2 }\end{array}$ & $\begin{array}{c}\text { Dengan } \\
\text { Sensor O2 }\end{array}$ \\
\hline 800 & 1.38 & 0.06 & 288 & 102 \\
\hline 1700 & 2.37 & 0.03 & 396 & 59 \\
\hline 2500 & 1.93 & 0.02 & 284 & 32 \\
\hline Rerata & 1.89 & 0.04 & 322.67 & 64.33 \\
\hline Selisih & \multicolumn{2}{|c|}{1.86} & \multicolumn{2}{|c|}{258.33} \\
\hline \% Penurunan & \multicolumn{2}{|c|}{$98 \%$} & \multicolumn{2}{|c|}{$80 \%$} \\
\hline
\end{tabular}

Hal tersebut menunjukkan bahwa pemasangan oksigen sensor terbukti mampu menurunkan kandungan emisi gas buang pada kendaraan kususnya pada mesin Toyota Avanza K3-VE.

Analisa perbandingan hasil eksperimen dengan peraturan hukum yang ada.
Selanjutnya analisa akan dilakukan dengan membandingkan hasil eksperimen dengan standar yang ada di indonesia. Dalam hal ini peneliti menggunakan acuan dari kementrian lingkungan hidup nomor 05 tahun 2006 seperti pada Tabel 4.

Tabel 4. Ambang batas gas buang kendaraan bermotor bahan bakar bensin (kep.No.05/men LH/08/2006) tanggal 1 Agustus 2006.

\begin{tabular}{|c|c|c|c|}
\hline NO & Emisi & Tahun & Maksimal \\
\hline 1 & CO $\%$ & $\geq 2007$ & $1.5 \%$ \\
\hline 2 & $\mathrm{HC}(\mathrm{ppm})$ & $\geq 2007$ & $200(\mathrm{ppm})$ \\
\hline
\end{tabular}

Perbandingan hasil uji dan standar dapat dilihat pada tabel perbandingan.

\section{Saat tanpa menggunakan $\mathrm{O}_{2}$ sensor}

Tabel 5. Hasil rata-rata pengujian kandungan emisi gas buang tanpa menggunakan $\mathrm{O}_{2}$ pada putaran $800 \mathrm{rpm}$.

\begin{tabular}{|c|c|c|}
\hline $\begin{array}{c}\text { Hasil } \\
\text { pengujian }\end{array}$ & Spesifikasi & Kondisi \\
\hline $\mathrm{CO}=1.38 \%$ & $\begin{array}{c}\text { Maks } \geq 2007= \\
1.5 \%\end{array}$ & Baik \\
\hline $\mathrm{HC}=288$ & $\begin{array}{c}\text { Maks } \geq 2007= \\
\text { ppm }\end{array}$ & Tidak Baik \\
\hline
\end{tabular}

Tabel 6. Hasil rata-rata pengujian kandungan emisi gas buang tanpa menggunakan $\mathrm{O}_{2}$ pada putaran $1700 \mathrm{rpm}$.

\begin{tabular}{|c|c|c|}
\hline $\begin{array}{c}\text { Hasil } \\
\text { pengujian }\end{array}$ & Spesifikasi & Kondisi \\
\hline $\mathrm{CO}=2.37 \%$ & $\begin{array}{c}\text { Maks } \geq 2007= \\
1.5 \%\end{array}$ & Tidak Baik \\
\hline $\begin{array}{c}\mathrm{HC}=396 \\
\mathrm{ppm}\end{array}$ & $\begin{array}{c}\text { Maks } \geq 2007= \\
200 \mathrm{ppm}\end{array}$ & Tidak Baik \\
\hline
\end{tabular}


Tabel 7. Hasil rata-rata pengujian kandungan emisi gas buang tanpa menggunakan $\mathrm{O}_{2}$ pada putaran $2500 \mathrm{rpm}$.

\begin{tabular}{|c|c|c|}
\hline $\begin{array}{c}\text { Hasil } \\
\text { pengujian }\end{array}$ & Spesifikasi & Kondisi \\
\hline $\mathrm{CO}=1.93 \%$ & $\begin{array}{c}\text { Maks } \geq 2007= \\
1.5 \%\end{array}$ & Tidak Baik \\
\hline $\begin{array}{c}\mathrm{HC}=284 \\
\text { ppm }\end{array}$ & $\begin{array}{c}\text { Maks } \geq 2007= \\
200 \mathrm{ppm}\end{array}$ & Tidak Baik \\
\hline
\end{tabular}

\section{Saat menggunakan $\mathrm{O}_{2}$ sensor}

Tabel 8. Hasil rata-rata pengujian kandungan emisi gas buang dengan menggunakan $\mathrm{O}_{2}$ sensor pada putaran 800 rpm.

\begin{tabular}{|c|c|c|}
\hline $\begin{array}{c}\text { Hasil } \\
\text { pengujian }\end{array}$ & Spesifikasi & Kondisi \\
\hline $\mathrm{CO}=0.06 \%$ & $\begin{array}{c}\text { Maks } \geq 2007= \\
1.5 \%\end{array}$ & Baik \\
\hline $\begin{array}{c}\mathrm{HC}=102 \\
\text { ppm }\end{array}$ & $\begin{array}{c}\text { Maks } \geq 2007= \\
200 \mathrm{ppm}\end{array}$ & Baik \\
\hline
\end{tabular}

Tabel 9. Hasil rata-rata pengujian kandungan emisi gas buang dengan menggunakan $\mathrm{O}_{2}$ pada putaran $1700 \mathrm{rpm}$.

\begin{tabular}{|c|c|c|}
\hline $\begin{array}{c}\text { Hasil } \\
\text { pengujian }\end{array}$ & Spesifikasi & Kondisi \\
\hline $\mathrm{CO}=0.03 \%$ & $\begin{array}{c}\text { Maks } \geq 2007= \\
1.5 \%\end{array}$ & Baik \\
\hline $\begin{array}{c}\mathrm{HC}=59 \\
\text { ppm }\end{array}$ & $\begin{array}{c}\text { Maks } \geq 2007= \\
200 \mathrm{ppm}\end{array}$ & Baik \\
\hline
\end{tabular}

Tabel 10. Hasil rata-rata pengujian kandungan emisi gas buang dengan menggunakan $\mathrm{O}_{2}$ pada putaran $2500 \mathrm{rpm}$.

\begin{tabular}{|c|c|c|}
\hline $\begin{array}{c}\text { Hasil } \\
\text { pengujian }\end{array}$ & Spesifikasi & Kondisi \\
\hline $\mathrm{CO}=0.02 \%$ & $\begin{array}{c}\text { Maks } \geq 2007= \\
1.5 \%\end{array}$ & Baik \\
\hline $\begin{array}{c}\mathrm{HC}=32 \\
\mathrm{ppm}\end{array}$ & $\begin{array}{c}\text { Maks } \geq 2007= \\
200 \mathrm{ppm}\end{array}$ & Baik \\
\hline
\end{tabular}

Dari tabel 4 hingga 10 dapat dibuat grafik perbandingan seperti pada gambar 8 dan 9 .

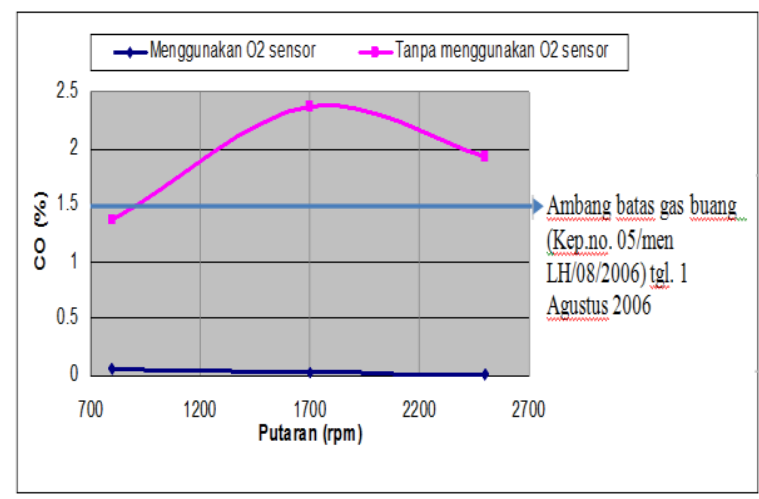

Gambar 8. Grafik perbandingan hasil pengujian kandungan $\mathrm{CO}$ pada emisi gas buang

Berdasarkan gambar 8 dan 9 dapat dilihat dan dianalisis pengaruh emisi gas buang yang dihasilkan menggunakan $\mathrm{O}_{2}$ sensor dan tanpa menggunkan $\mathrm{O}_{2}$ sensor yaitu sebagai berikut: Berdasarkan hasil pengujian yang telah dilakukan, penulis dapat menyimpulkan bahwa, pada kondisi mesin putaran 800 rpm Toyota Avanza K3$\mathrm{VE}$ tanpa menggunakan $\mathrm{O}_{2}$ sensor kandungan $\mathrm{CO}$ dalam kondisi baik (dalam batas yang diizinkan sesuai dengan ambang batas gas buang kendaraan bermotor Kep. No. 05/MenLH/08/2006 Tgl. 1 Agustus 2006) dan HC yang dihasilkan yaitu 288 ppm dalam kondisi tidak baik (melebihi batas yang diizinkan sesuai dengan ambang batas gas buang kendaraan bermotor Kep. No. 05/MenLH/08/2006 Tgl. 1 Agustus 2006) . 


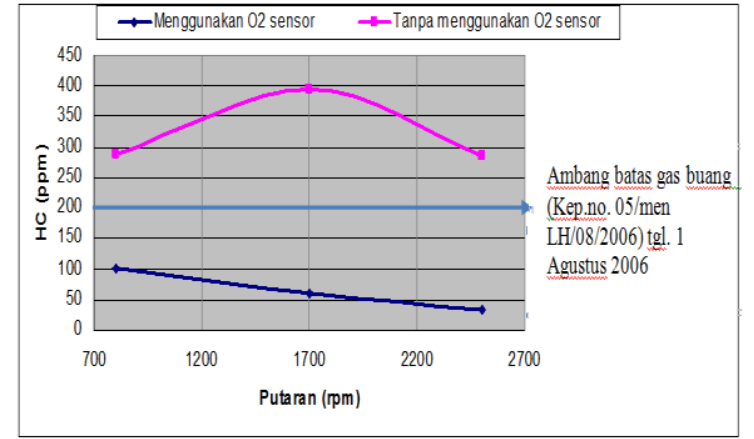

Gambar 9. Grafik perbandingan hasil pengujian kandungan $\mathrm{HC}$ pada emisi gas buang

Pada kondisi putaran mesin $1700 \mathrm{rpm}$ Toyota Avanza K3-VE tanpa $\mathrm{O}_{2}$ sensor kandungan $\mathrm{CO}$ yang dihasilkan yaitu $2.37 \%$ dan HC yaitu $396 \%$ dalam kondisi tidak baik (melebihi batas yang diizinkan sesuai dengan ambang batas gas buang kendaraan bermotor Kep. No. 05/MenLH/08/2006 Tgl. 1 Agustus 2006).

Pada kondisi putaran mesin $2500 \mathrm{rpm}$ Toyota Avanza K3-VE tanpa $\mathrm{O}_{2}$ sensor kandungan $\mathrm{CO}$ yang dihasilkan yaitu $1.93 \%$ dan HC yaitu 284 ppm mengalami penurunan pada kondisi putaran mesin 1700 dalam kondisi tidak baik (melebihi batas yang diizinkan sesuai dengan ambang batas gas buang kendaraan bermotor Kep. No. 05/MenLH/08/2006 Tgl. 1 Agustus 2006). Hal ini berarti volume penginjeksian bahan bakar gemuk (kaya), bensin belum terbakar dengan sempurna diruang bakar. Volume penginjeksian bahan bakar yang gemuk ini disebabakan karena tidak adanya informasi keadaan udara bensin yang harus diterima oleh ECU sehingga ECU tidak mengurangi atau menambah volume penginjeksian bahan bakar.

Sedangkan untuk kondisi dengan sensor oksigen terpasng dapat disimpulkan bahwa pada putaran mesin $800 \mathrm{rpm}, 1700 \mathrm{rpm}$, 2500 rpm Toyota Avanza K3-VE kandungan $\mathrm{CO}$ dan $\mathrm{HC}$ yang dihasilkan dalam kondisi baik (dalam batas yang diizinkan sesuai dengan ambang batas gas buang kendaraan bermotor Kep. No. 05/MenLH/08/2006 Tgl. 1 Agustus 2006). Hal ini berarti volume penginjeksian bahan bakar ideal dan proses pembakaran mendekati sempurna. Volume penginjeksian dapat mendekati perbandingan ideal dihasilkan berdasarkan sinyal dari oksigen sensor, maka ECU akan menambah atau mengurangi volume penginjeksian agar perbandingan udara dan bahan bakar ideal (mendekati perbandingan teoritis). Dengan menggunakan oksigen sensor dapat membantu kerja katalitik konverter untuk mereduksi kadar kandungan emisi yaitu $\mathrm{CO}$ dan HC supaya dapat lebih optimal.

Kandungan emisi gas buang $\mathrm{CO}, \mathrm{HC}$ mengalami kenaikan pada saat tidak menggunakan oksigen. Jika CO semakin besar menunjukan bahwa volume penginjeksian bahan bakar gemuk (kaya). Tinggi rendahnya angka $\mathrm{CO}$ ditentukan campuran bahan bakar dengan udara yang ideal. Bahwa untuk mememproleh emisi yang berwawasan lingkungan diperlukan perbandingan campuran ideal atau yang mendekati ideal disegala kondisi operasional motor. Untuk mendapatkan perbandingan campuran yang ideal tersebut dibutuhkan informasi keadaan campuran udara bensin yang harus diterima oleh ECU, informasi/sinyal diterima dalam bentuk tegangan berdasarkan kadar oksigen yang ada pada saluran gas buang, fungsi tersebut dilakukan oleh oksigen sensor.

Jika HC semakin kecil menunjukan bahan bakar sudah terbakar mendekati sempurna. Pembakaran yang tidak sempurna di ruang bakar merupakan penyebab tingginya kandungan $\mathrm{HC}$ di gas buang.

Sehingga dapat ditarik kesimpulan sensor oksigen dapat mempengaruhi kandungan emisi gas buang, maka kandungan emisi gas buang menggunakan $\mathrm{O}_{2}$ sensor lebih rendah dan ramah lingkungan dari pada tanpa menggunakan $\mathrm{O}_{2}$ sensor.

\section{SIMPULAN}

Hasil penelitian menunjukkan bahwa pemasangan sensor oksigen pada mesin kendaraan mampu menurunkan kandungan berbahaya dari emisi gas buang khususnya $\mathrm{CO}$ dan $\mathrm{HC}$. 
Penelitian menunjukkan untuk mesin Toyota Avanza K3-VE dengan Oksigen sensor didapatkan penurunan persentase kandungan CO sebesar $1.86 \%$ dan rerata jumlah ppm yang berkurang pada $\mathrm{HC}$ sebanyak $258.33 \mathrm{ppm}$

Dari hasil penelitian juga didapatkan bahwa dengan menggunakan oksigen sensor tingkat emisi gas buang mesin Toyota Avanza K3-VE telah memenuhi standar emisi gas buang yang ditetapkan oleh peraturan yang berlaku di Indonesia.

\section{SARAN}

Bagi penelitian selanjutnya perlu diuji juga untuk jenis kendaraan yang lain.

\section{DAFTAR PUSTAKA}

Fardiaz, Srikandi. (1992). Polusi Air \& Udara. Bogor : Kanisius.

J.Marek, H.-P.Trah, Y.Suzuki, I.Yokomori (2003). Sensors for Automotive Applications. Weinheim : WILEY-VCH Verlag $\mathrm{GmbH}$ \& Co.

PT. Toyota Astra Motor. (2004). Toyota Computer Controlled System. Jakarta : PT Toyota Astra Motor.

PT. Honda Prospect Motor. (2002). Manual Shop Honda Jazz/Fit. Jakarta : PT. Honda Prospect Motor.

Suyanto, Wardan. (1989). Teori Motor Bensin. Jakarta : Depdikbut, Dirjen Pendidikan Tinggi PPLPTK.

Wardhana, Arya Wisnu. (2004). Dampak Pencemaran Lingkungan. Yogyakarta : Andi Yogyakarta. 